This item was submitted to Loughborough's Research Repository by the author.

Items in Figshare are protected by copyright, with all rights reserved, unless otherwise indicated.

\title{
Optimal power flow in VSC-HVDC networks for DC-ISO: constant current operation
}

\section{PLEASE CITE THE PUBLISHED VERSION}

http://dx.doi.org/10.1109/ISGT-Asia.2015.7387066

PUBLISHER

(C) IEEE

\section{VERSION}

AM (Accepted Manuscript)

\section{PUBLISHER STATEMENT}

This work is made available according to the conditions of the Creative Commons Attribution-NonCommercialNoDerivatives 4.0 International (CC BY-NC-ND 4.0) licence. Full details of this licence are available at: https://creativecommons.org/licenses/by-nc-nd/4.0/

\section{LICENCE}

CC BY-NC-ND 4.0

\section{REPOSITORY RECORD}

Gonzalez-Longatt, Francisco M.. 2019. "Optimal Power Flow in VSC-HVDC Networks for DC-ISO: Constant Current Operation”. figshare. https://hdl.handle.net/2134/20512. 


\title{
Optimal Power Flow in VSC-HVDC Networks for DC- ISO: Constant Current Operation
}

\author{
F. González-Longatt \\ School of Electrical, Electronic and System Engineering \\ Loughborough University \\ Loughborough, LE11 3TU, United Kingdom \\ fglongatt@,fglongatt.org
}

\begin{abstract}
DC Independent System Operator (DC-ISO) is a revolutionary concept; a single entity designed to coordinate, to control and monitor the operation of the DC transmission system. It will be responsible for ensuring the reliability and security of the $V S C-H V D C$ meshed networks in real-time and co-ordinate the supply of and demand for electricity, in a manner that avoids violations of technical and economic standards. This paper proposes a simple methodology for optimal power flow (OPF) allowing constant current operation in a series branch of the VSC-HVDC network in order to cope with one the possible DCISO objectives. One of the contribution of this paper is a methodology that allows including new operator objectives as in the OPF problem as a type linear equality constraints, it is based on nodal analysis. Proposed methodology has been thoroughly illustrated and tested with a simple 3-node MVSCDC system, and results show the validity of the proposed approach.
\end{abstract}

Index Terms-HVDC, Optimal Power Flow, Transmission system operator.

\section{INTRODUCTION}

Energy Roadmap 2050 proposed by the European Commission (EC) is based on the reduction of the greenhouse gas emissions to $80 \%-95 \%$ below 1990 levels by 2050 . To fulfill the Energy Roadmap 2050, a dramatic reduction in electricity generation sector is required, it can be done maximizing the power contribution coming from offshore wind power plants distant from the shore. DC transmission networks appear as a very eye-catching solution for the network integration of this wind power [1].

High Voltage DC (HVDC) transmission system based on Voltage Source Converter (VSC) enables the use of complex configuration as the multi-terminal HVDC for the integration of large-scale wind power in the North Sea. Also, a panEuropean transmission network is required in order to balancing and transportation of electricity in order to reach the objective of the one single European market [1], [2]. Multiterminal VSC-HVDC (MVSCDC) offers higher reliability, redundant and flexible technology to enable the massive integration of offshore wind power in future power systems. The European Network of Transmission System Operators for
Electricity (ENTSO-E) [3], the association of Europe's transmission system operators (TSOs) for electricity, recognize the importance of a pan-European transmission system to enforce energy policy goals (sustainability, competitiveness/market integration and energy security) and promote the idea of a Supergrid as an answer to European energy needs [4]. The new Network Code on HVDC connections (NC HVDC) [5] sets out the rules and requirements that will cover $\mathrm{HVDC}$ technology. The $\mathrm{NC}$ covers HVDC connections between different parts of Europe, as well as specifying the connection rules applying to the generators, which are connected to the main electricity systems via HVDC lines. Also, the NC HVDC promotes investments in infrastructure in a non-discriminatory way, fair access to the network for new entrants and transparency in the market. These conditions make possible the rise of a new transmission system model, the DC-Independent System Operator (DCISO) [6]. DC-ISO is defined in this paper as a private or public entity, and it to coordinates, controls and monitors the operation of the DC transmission system involving one or several power park modules and one or several TSOs. DC-ISO is expected to perform the same functions as ISOs, but cover only the MVSCDC system. The DC-ISO will be responsible for ensuring the reliability and security of the MVSCDC system in real-time and co-ordinate the supply of and demand for electricity, in a manner that avoids violations of technical and economic standards.

The operation scope of a DC-ISO includes HVDC Systems connecting: synchronous areas or control areas, power park modules to a transmission network or a distribution network, and potentially embedded HVDC systems. Considering the possible structure of the North Sea Supergrid (NSS), it is possible to define me main concern of its DC-ISO on the MVSCDC system connecting offshores and onshore infrastructures, this paper is focused in this approach. Different operational control modes can be set by the $D C$ - DC-ISO to the onshore grid side converters (GSC) due to the varying nature on power injection of the wind farm side converter (WFSC) at each offshore wind power plants (WPP). 
DC voltage is the essential factor that indicates the power balance and the stability of an MVSCDC system. Several DCvoltage control strategies are suggested on the literature and categorized as [7]: centralized DC slack bus control, voltage margin control and distributed voltage droop control.

Voltage droop control represent a robust control scheme for MVSCDC systems without the need for communication systems; but this control scheme have several undesirable features: potentially higher or lower voltages during and after contingencies, it cannot cope with an outage or blocking of the DC voltage controlling converter [8], etc. Several publications [7-12] present solutions to the problem of optimal steady-state operation of the MVSCDC systems considering voltage droop controller [2] and others. However, the main focus of those papers is on minimizing the power losses in MVSCDC for large offshore wind power plants or a transnational Supergrid.

The author accepts disbelief and even scepticism about DCISO concepts but recognizes a potential business opportunity for this entity on the future NSS. Several objectives (beyond losses minimization) can be identified by the DC-ISO based on the systems interactions: markets, security, offshore wind power uncertainty, etc. Virtually every single possible steadystate operating point can be objective can be optimally and centralized defined in an adequate time-scale and set-points send to the converter stations.

This paper presents a methodology for an optimal steadystate operation of a MVSCDC system based on DC-ISO objectives. DC-ISO might use a path inside the MVSCDC as interconnectors for international electricity trade allowing inter TSO operation; under this condition the power flow direction $\left(P_{i j}\right)$ in one or several undersea cable inside the MVSCDC must be loaded at very specific value under variables conditions. Also, one consequence of the losses minimization is the tendency to booster the voltage profile inside the MVSCDC which can create dangerous over-voltages during contingencies, DC-ISO might decide to sacrifice a small portion of the losses in order to set a voltage profile with less impact under $N-1$ conditions. This paper presents a combination of single-objective function and enhanced constraints solve the problem optimal operation of a MVSCDC system based on DC-ISO objectives.

The paper is organized as follows: Section II briefly defines the main considerations about DC-ISO and Section III establishes the short backgrounds about DC-voltage control in MVSCDC systems. Section IV focuses the proposed optimal power flow in system based on DC-ISO objectives. Section V illustrates application examples on a representative test system of a future DC-ISO. Section 6 concludes.

\section{DC INDEPENDENT SYSTEM OPERATOR (DC-ISO)}

The introduction of HVDC grids brings with it major challenges, and opportunities. It has being recognized by ENTSO-E by creation of the most recent draft Network Code on High Voltage Direct Current Connections and DCconnected Power Park Modules. It establishes rules for HVDC
Systems and a common framework for connection agreements between network operators and all agents involved. Network Code established that any natural or legal entity is allowed to owning or developing a HVDC System HVDC. It opens the door to promote investments in infrastructure in a nondiscriminatory way, fair access to the network for new entrants and transparency in the market "[EU law 2009/72/EC]".

The most popular European Model on transmission system is the Ownership Unbundling (OU) and using this clear-cut separation two possible scenarios are possible on HVDC systems: (i) DC-Independent System Operator (DC-ISO): a fully unbundled HVDC System Operators without the grid assets (still belonging to an integrated company) and (ii) $D C$ Independent Transmission Operators (DC-ITO): a DC Transmission System Operator owning the assets and belonging to a vertically integrated company, with special rules to guarantee its independence. In this paper, DC-ISO is defined as a private or public entity, and it to coordinates, controls and monitors the operation of the DC transmission system involving one or several power park modules and one or several TSOs [6]. DC-ISO is expected to perform the same functions as ISOs, but cover only the MVSCDC system.

\section{OPTIMAL POWER Flows IN MVSCDC}

\section{A. Problem of $O P F$}

Optimal power flow (OPF) is a common tool used for the optimization of a given AC power system network. The idea of an OPF algorithm is to find a set of values of the network parameters which will optimize one (or more) the system's functionalities [13], i.e. system power losses, total generation cost, operational limits, or system security. DC-ISO will uses the OPF in order to dispatch the MVSCDC according to signals provided by the pool market [6]. The steady-state behaviour of a MVSCDC system can be described by a set of nonlinear set of the algebraic equations:

$$
\mathbf{G}(\mathbf{X}, \mathbf{Y})=\mathbf{0}
$$

where $\mathbf{G}$ is the set of algebraic equations define the power balance at network buses as shown in (5), and $\mathbf{A}$ is state vector and $\mathbf{B}$ is the vector of independent variable. The state vector contains the state variables describing the state of the MVSCDC system, it contain dependent variables. DC voltages can be dependent or independent variables depending on the voltage control used. Slack node and other voltage-type nodes provides known or independent variables contained in $\mathbf{B}$.

OPF is formulated mathematically as a general constrained optimization problem where set of constraints are taking in account. The most basic and general OPF formulation is based on a problem of minimization without inequality constraints as:

$$
\min \mathbf{F}(\mathbf{A}, \mathbf{B})
$$

Subject to:

$$
\mathbf{G}(\mathbf{A}, \mathbf{B})=0
$$

where $\mathbf{F}(\mathbf{A}, \mathbf{B})$ is the function to be optimized. 


\section{B. Definition of Objective Function}

The problem of optimizing the performance of a MVSCDC system is formulated as general optimization problem. It is required to state from which point of view the performance of the system will be optimized. In the classical problem of OPF, the objective function is "to minimize the overall generating cost"

Most of the published OPF algorithms seek to optimize only one objective function, however, many other objective functions are possible [14]: minimize changes in controls, minimize system losses, maximize security, etc. After a literature review, the number of published paper contributed to the OPF multi-objective problem is small [14], and the favourite combined objectives may include, generating cost, environmental variables and security. In terms of OPF, the most used objective function is minimize the system losses as is applied on [9], [13], etc. DC-ISO coordinates, controls and monitors the operation of the MVSCDC involving one or several power park modules and one or several TSOs, as consequence minimize the system losses is expected to be one priority on optimal steady-state operation.

In this paper, system loses are located on the DC transmission system and it is assumed to be the Joule heating or ohmic heating in the cables. Under the previous assumption, the total losses in a MVSCDC system can be written as:

$$
\mathbf{F}(\mathbf{A}, \mathbf{B})=P_{\text {losses }}=\sum_{i=1}^{n_{d c}} P_{d c, i}
$$

where $P_{d c, i}$ are the elements in $\mathbf{P}_{\mathrm{dc}}$ calculated in terms of the nodal voltages using (5).

\section{Definition of Constraints}

The OPF in MVSCDC is a mathematical optimization problem, typically called constraint optimization. In this process, the objective function, $\mathbf{F}(\mathbf{A}, \mathbf{B})$, is optimized with respect to some variables in the presence of constraints on those variables. The constraints divide the searching space into two domains, the feasible domain where the constraints are satisfied, and the infeasible domain where at least one of the constraints is violated. In general terms, the OPF problem may include several special forms for constraints: nonlinear constraints, bound constraints, linear inequality constraints, and linear equality constraints. A description of the definition of the constraints used in this paper are presented on the next sections.

\section{1) Bound constraints}

VSC converters are used to control DC voltage inside MVSCDC. Those power converters, usually use IGBTs as commutation devices which are extremely sensible and have very low capacity to cope with voltages changes. DC overvoltage which may stress the commutation devices and extremely low under-voltages can cause destructive overcurrent on the IGBT. As consequence there are limits with regard to steady state voltage ranges at the converter stations. In this paper, the $i$-th node DC-voltage at station converters
$\left(U_{d c, i}\right)$ are written as bound constraints based on operational limits:

$$
U_{\text {min }}<U_{d c, i}<U_{\text {max }}
$$

where $U_{\min }$ and $U_{\max }$ represent the minimum and maximum allowed voltage. The use of bound constraints allow met technical operational limits but at the same time, there is a mathematical advantages because allow to obtain faster and more reliable solutions because the searching space is reduced.

\section{2) Nonlinear equality constraints}

Nonlinear inequality constraints have the form $\mathbf{G}(\mathbf{A}, \mathbf{B})=\mathbf{0}$, where $\mathbf{G}$ is a vector of constraints, one component for each constraint. The mathematical formulation of the OPF includes a set of nonlinear equality constraints as presented (8). The constraints represent the power balance at each node or power flow equations as described in (5). In most practical problems the minimum is found on the boundary between the feasible and infeasible domains, that is at a point where $\mathbf{G}(\mathbf{A}, \mathbf{B})=\mathbf{0}$.

\section{3) Linear inequality constraints}

There is a very strict current limitation on VSC converter used in MVSCDC systems. The power converter commutation devices, usually IGBTs, have very little, if any, overcurrent capacity. The VSC control system will make sure that the converter valves maximum current is not exceeded. Linear inequalities constraints is used in the OPF problem of MVSCDC to represent the maximum current limit in converters:

$$
\text { I }_{\text {conv }}<\text { I }_{\text {conv }}^{\text {max }}
$$

where $\mathbf{I}_{\text {conv }}^{\max }$ represents a vector containing the maximum loading current allow in each converter station. Using the nodal analysis, the nodal current can be transformed using (3) into a set of linear inequalities constraints as follow:

$$
\mathbf{I}_{\text {conv }}=\mathbf{Y}_{\mathrm{dc}} \mathbf{U}_{\mathrm{dc}}<\mathbf{I}_{\text {conv }}^{\text {max }}
$$

\section{4) Linear equality constraints}

The linear equality constraints are really important in this paper because allow to define one potential interest of the DCISO. The DC-ISO will be responsible for ensuring the reliability and security of the MVSCDC system in real-time and co-ordinate the supply of and demand for electricity, in a manner that avoids violations of technical and economic standards.

Let consider a massive meshed MVSCDC, the DC-ISO might be interested on the use of a very specific branch or a very specific path inside the MVSCDC system, such can be the case of define a secure path as interconnectors between international TSO to allow the international electricity trade Under this scenario, the power flow direction and value in one or several branches, undersea cables, inside the MVSCDC must be loaded at very fixed and specific value under any variables operation condition. This operation mode can be transformed into linear equality constraints.

Let consider the domain of a DC-ISO inside a MVSCDC, and let assume the DC-ISO is interest operates a single branch between node $i$ and $j$ a constant current, independently of the system variations. 
The current flowing through the cable connected between node $i$ and node $j, I_{i j}$, is written using nodal analysis as:

$$
I_{i j}=Y_{i, i}\left(U_{d c, i}-U_{d c, j}\right)=I_{i j}^{e s p}
$$

where $Y_{i, j}$ is the correspondent element of the $\mathbf{Y}_{\mathbf{D C}}$ is the DC nodal admittance matrix, and $I_{i j}{ }^{e s p}$ represents the operational current defined by the DC-ISO for that specific branch.

The use of current in this constrain is preferred over power because limit the power transfer of submarine cables are typically defined by the thermal limits (ampacity).

\section{Simulation AND Results}

In this Section, a multi-terminal VSC-HVDC test network is used to illustrate and test the optimal power flow proposed in this paper. A MATLAB ${ }^{\circledR}$ R2014a [15] (version 8.3.0.532 64bit) program ( $m$-file) has been developed for this very specific propose.

\section{A. Test System}

A 3-terminal, $\pm 200 \mathrm{kVdc}, \quad$ VSC-HVDC network representative of the integration of offshore wind power coming from the North Sea is used for illustrative purposes (see Fig. 2). All converter stations use symmetrical bi-pole topology using two different DC voltage control modes on the VSC-HVDC terminals: constant power control mode on the wind farm converter station (WFC1) and voltage control on the grid side converter stations $\left(\mathrm{GSC}_{\mathrm{i}}, i=1\right.$ and 2$)$.

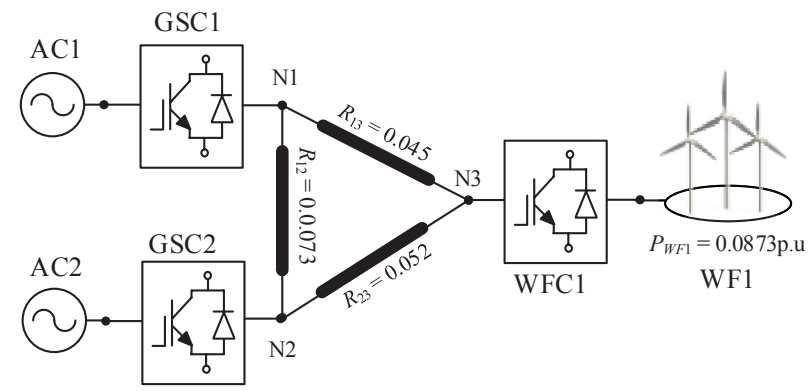

Fig. 1. Test system I: Values of resistors $R_{i j}$ are shown in p.u.

\section{B. Scenarios}

This test is designed to present a compressive analysis all possible features of the proposed methodology for optimal power flow calculation. In this subsection, simulation scenarios are defined considering three aspects: (i) Constraints and (ii) Contingencies. The offshore wind farm converter station is selected to operate in constant power control mode in all simulations. GSC1 and GSC2 can be enabled with controllers for DC voltage regulation.

\section{1) Operational constraints}

Bound constraints are considered in all simulations in order to ensure a secure system operation $\left(0.90<U_{d c}<1.10 \mathrm{p} . \mathrm{u}\right)$.

Three scenarios are considered in this paper in order to demonstrate the impact of operational constraints in branches: (I) No constraints in any under-sea cable scenario is used to illustrate the optimal solution of the power flow where only system's losses are minimized. Then, linear equality constraints are used to define a realistic operational constraint as is expected by the DC-ISO. The current in one system's branch, under-sea cable, inside the test system is defined to be constant for any operational condition. Current across the cable 12 is selected for illustrative purposes, however, it can be extended to any other case e.i. $P_{i j}$, etc. Two scenarios are used here to illustrated the effect of branch constraints: (II) $I_{12}=$ 0.50 p.u. and (III) $I_{12}=-0.80$ p.u. Changing the current direction the author demonstrate the flexibility in operational constraint that can be included in the proposed methodology.

\section{2) Cable Contingencies}

The DC operator entity will be responsible of the reliability and security of the of the DC transmission system, as consequence, steady-state performance of the DC system after contingencies must be evaluated to ensure appropriate operation. In this paper, four contingency scenarios $(1, \ldots, 4)$ are considered, a summary of them is presented in Table 1. Converter outages are not considered in this paper.

TABLE 1. SUMMARY OF SiMUlation SCENARIOS

\begin{tabular}{c|l}
\hline \hline \multicolumn{2}{c}{ Scenario Definition: Operational Constraint } \\
\hline Code & \multicolumn{1}{c}{ Description } \\
\hline$I$ & No Constraint \\
$I I$ & Constraint $I_{12}=0.80$ p.u. \\
III & Constraint $I_{12}=-0.80$ p.u \\
\hline \hline \multicolumn{2}{|c}{ Scenario Definition: Contingency } \\
\hline Code & \multicolumn{1}{c}{ Description } \\
\hline 1 & No Contingency \\
2 & Cable 13 outage \\
3 & Cable 23 outage \\
4 & Cable 12 outage \\
\hline
\end{tabular}

\section{Numerical Results of $O P F$}

The numerical results of the OPF using the proposed methodology for all simulation scenarios (as shown on Table 1) are presented in Table 2, 3 and 4. Optimal solution are found on all simulation scenarios if no branch constraints are considered (Scenario I), and losses are minimal for those cases.

The participation of GSC1 and GSC2 on DC-voltage regulation allows the optimal operation of the MVSCDC fulfilling all the considered constraints. The effect of branch constraints is to define a power flow between N1 and N2: (II) $I_{12}=0.50$ p.u. and (III) $I_{12}=-0.50$ p.u. However, those constrains require an overrated grid side converter stations (GSC) in order to cope with the additional power.

TABLE 2. Simulation Results OF OPF: VolTAGES $\left(U_{I}\right)$ AND POWER INJECTIONS $\left(P_{1}\right)$

\begin{tabular}{c|c|ccc|ccc}
\multicolumn{2}{c}{ Scenario } & $U_{1}$ & $U_{2}$ & $U_{3}$ & $P_{G S C 1}$ & $P_{G S C 2}$ & $P_{W F C 3}$ \\
\hline \multirow{4}{*}{1} & $I$ & 1.0912 & 1.0912 & 1.1000 & -0.425 & -0.368 & 0.8 \\
& $I I$ & 1.0416 & 1.1000 & 1.0776 & $\mathbf{- 3 . 3 3 5}$ & $\mathbf{2 . 7 0 6}$ & 0.8 \\
& $I I I$ & 1.1000 & 1.0416 & 1.0818 & $\mathbf{2 . 6 4 9}$ & $\mathbf{- 3 . 2 7 8}$ & 0.8 \\
\hline \multirow{4}{*}{2} & $I$ & 1.0811 & 1.0811 & 1.1000 & 0.000 & -0.786 & 0.8 \\
& $I I$ & 1.0227 & 1.0811 & 1.1000 & $\mathbf{- 1 . 6 3 6}$ & 0.944 & 0.8 \\
& $I I I$ & 1.1000 & 1.0416 & 1.0612 & $\mathbf{1 . 7 6 0}$ & $\mathbf{- 2 . 4 5 2}$ & 0.8 \\
\hline \multirow{3}{*}{3} & $I$ & 1.0811 & 1.0811 & 1.1000 & 0.000 & -0.786 & 0.8 \\
& $I I$ & 1.0227 & 1.0811 & 1.1000 & $\mathbf{- 1 . 6 3 6}$ & 0.944 & 0.8 \\
& $I I I$ & 1.1000 & 1.0416 & 1.0612 & $\mathbf{1 . 7 6 0}$ & $\mathbf{- 2 . 4 5 2}$ & 0.8 \\
\hline \multirow{4}{*}{4} & $I$ & 1.0912 & 1.0912 & 1.1000 & -0.425 & -0.368 & 0.8 \\
& $I I$ & 1.0416 & 1.1000 & 1.0776 & $\mathbf{- 3 . 3 3 5}$ & $\mathbf{2 . 7 0 6}$ & 0.8 \\
& $I I I$ & 1.1000 & 1.0416 & 1.0818 & $\mathbf{2 . 6 4 9}$ & $\mathbf{- 3 . 2 7 8}$ & 0.8 \\
\hline
\end{tabular}


TABle 3. Simulation Results of OPF: BRANCH CURRENTS $\left(I_{I J}\right)$ AND POWER FLOWS $\left(P_{I J}=U_{I}^{*} I_{I J}\right)$

\begin{tabular}{c|c|ccc|ccc}
\multicolumn{2}{c}{ Scenario } & $I_{12}$ & $I_{23}$ & $I_{13}$ & $P_{12}$ & $P_{23}$ & $P_{13}$ \\
\hline \multirow{4}{*}{1} & $I$ & 0.000 & -0.169 & -0.210 & 0.000 & -0.185 & -0.229 \\
& $I I$ & $\mathbf{- 0 . 8 0 0}$ & 0.431 & -0.857 & -0.833 & 0.474 & -0.943 \\
& $I I I$ & $\mathbf{0 . 8 0 0}$ & -0.773 & 0.433 & 0.880 & -0.805 & 0.451 \\
\hline \multirow{4}{*}{2} & $I$ & 0.000 & -0.363 & -0.450 & 0.000 & -0.393 & -0.486 \\
& $I I$ & $\mathbf{- 0 . 8 0 0}$ & -0.363 & $\mathbf{- 1 . 8 4 0}$ & -0.818 & -0.393 & $\mathbf{- 1 . 9 9 0}$ \\
& $I I I$ & $\mathbf{0 . 8 0 0}$ & -0.377 & 0.924 & 0.880 & -0.393 & 0.962 \\
\hline \multirow{4}{*}{3} & $I$ & 0.000 & -0.363 & -0.450 & 0.000 & -0.393 & -0.486 \\
& $I I$ & $\mathbf{- 0 . 8 0 0}$ & -0.363 & $-\mathbf{- 1 . 8 4 0}$ & -0.818 & -0.393 & $-\mathbf{- 1 . 9 9 0}$ \\
& $I I I$ & $\mathbf{0 . 8 0 0}$ & -0.377 & 0.924 & 0.880 & -0.393 & 0.962 \\
\hline \multirow{4}{*}{4} & $I$ & 0.000 & -0.169 & -0.210 & 0.000 & -0.185 & -0.229 \\
& $I I$ & $\mathbf{- 0 . 8 0 0}$ & 0.431 & -0.857 & -0.833 & 0.474 & -0.943 \\
& $I I I$ & $\mathbf{0 . 8 0 0}$ & -0.773 & 0.433 & 0.880 & -0.805 & 0.451 \\
\hline
\end{tabular}

TABle 3. SimUlation RESUltS OF OPF: BRANCH LOSSES $\left(\right.$ LOSSES $\left._{I J}\right)$ AND TOTAL LOSSES

\begin{tabular}{c|c|ccc|c}
\hline \hline \multicolumn{2}{c|}{ Scenario } & Loss $_{12}$ & Loss $_{23}$ & Loss $_{13}$ & $\begin{array}{c}\text { Total } \\
\text { Loss }\end{array}$ \\
\hline \multirow{4}{*}{1} & $I$ & 0.00000 & 0.00149 & 0.00184 & $\mathbf{0 . 0 0 3 3 3}$ \\
& $I I$ & 0.04672 & 0.00965 & 0.03086 & 0.08723 \\
& $I I I$ & 0.04672 & 0.03108 & 0.00789 & 0.08568 \\
\hline \multirow{4}{*}{2} & $I$ & 0.00000 & 0.00687 & 0.00851 & $\mathbf{0 . 0 1 5 3 7}$ \\
& $I I$ & 0.04672 & 0.00687 & 0.14227 & 0.19586 \\
& $I I I$ & 0.04672 & 0.00739 & 0.03584 & 0.08995 \\
\hline \multirow{3}{*}{3} & $I$ & 0.00000 & 0.00687 & 0.00851 & $\mathbf{0 . 0 1 5 3 7}$ \\
& $I I$ & 0.04672 & 0.00687 & 0.14227 & 0.19586 \\
& $I I I$ & 0.04672 & 0.00739 & 0.03584 & 0.08995 \\
\hline \multirow{3}{*}{4} & $I$ & 0.00000 & 0.00149 & 0.00184 & $\mathbf{0 . 0 0 3 3 3}$ \\
& $I I$ & 0.04672 & 0.00965 & 0.03086 & 0.08723 \\
& $I I I$ & 0.04672 & 0.03108 & 0.00789 & 0.08568 \\
\hline \multirow{2}{*}{} & & & & &
\end{tabular}

\section{CONCLUSIONS}

The author accepts disbelief and even scepticism about DCISO concepts but recognizes a potential business opportunity for this entity on the future MVSCDC. DC-ISO will be a single coordinate, to control and monitor the operation of the DC transmission system. It will be responsible for ensuring the reliability and security of the MVSCDC system in real-time and co-ordinate the supply of and demand for electricity, in a manner that avoids violations of technical and economic standards.

This paper proposes a simple methodology for OPF allowing the DC-ISO objectives to be included in the solution. The OPF problem is formulate to minimize the total system losses and technical constraints are included (nonlinear, bound, linear inequality and linear equality constraints). A contribution of this paper is include one operational objective of future DCISO into the OPF.

DC-ISO might use a path inside the MVSCDC as interconnectors for international electricity trade allowing inter TSO operation; under this condition the current magnitude and direction in one or several undersea cable inside the MVSCDC must be loaded at very specific value under variables conditions. This paper proposes the use of a type linear equality constraints based on nodal analysis to include this specific operational mode to the OPF.
Proposed methodology has been illustrated and tested with a very simple 3-node MVSCDC system interconnecting and offshore wind farm to two independent AC systems. Results show the implications of the number of converters stations regulating DC voltage and several aspects of the OPF (simulation time, quality of solution, etc.)

\section{REFERENCE}

[1] F. Gonzalez-Longatt, "Frequency Control and Inertial Response Schemes for the Future Power Networks," in Advances in Technologies for Generation, Transmission and Storage, Green Energy and Technology Series. vol. VIII, J. Hossain and A. Mahmud, Eds., ed Singapur: SpringerVerlag, 2014, p. 363.

[2] F. Gonzalez-Longatt, J. M. Roldan, and C. A. Charalambous, "Solution of ac/dc power flow on a multiterminal HVDC system: Illustrative case supergrid phase I," in 47th International Universities Power Engineering Conference (UPEC 2012), 2012, pp. 1-7.

[3] ENTSO-e. (2014). European Network of Transmission System Operators for Electricity -ENTSO-e Website. Available: https://www.entsoe.eu/Pages/default.aspx

[4] ENTSO-E. (2014). Continental Europe Operation Handbook. Available: https://www.entsoe.eu/publications/system-operationsreports/operation-handbook/Pages/default.aspx

[5] ENTSO-e, "ENTSO-E Draft Network Code on High Voltage Direct Current Connections and DC-connected Power Park Modules," ENTSOe, Avenue Cortenbergh 100, 1000 Brussels, Belgium, Draft10/03/14 2014.

[6] F. Gonzalez-Longatt, "Optimal Steady-State Operation of a MTDC system based on DC-Independent System Operator Objectives " presented at the The 11th International Conference on AC and DC Power Transmission, Birmingham, UK, 2014.

[7] W. Wenyuan and M. Barnes, "Power Flow Algorithms for MultiTerminal VSC-HVDC With Droop Control," Power Systems, IEEE Transactions on, vol. 29, pp. 1721-1730, 2014.

[8] J. Beerten, S. Cole, and R. Belmans, "Modeling of Multi-Terminal VSC HVDC Systems With Distributed DC Voltage Control," Power Systems, IEEE Transactions on, vol. 29, pp. 34-42, 2014.

[9] M. Aragüés-Peñalba, A. Egea-Àlvarez, O. Gomis-Bellmunt, and A. Sumper, "Optimum voltage control for loss minimization in HVDC multi-terminal transmission systems for large offshore wind farms," Electric Power Systems Research, vol. 89, pp. 54-63, 8// 2012.

[10] A. K. Marten and D. Westermann, "A novel operation method for meshed HVDC overlay grids and corresponding steady state and dynamic power flow calculation principle," in $A C$ and DC Power Transmission ( $A C D C$ 2012), 10th IET International Conference on, 2012, pp. 1-6.

[11] S. Rodrigues, R. T. Pinto, P. Bauer, E. Wiggelinkhuizen, and J. Pierik, "Optimal power flow of VSC-based multi-terminal DC networks using genetic algorithm optimization," in Energy Conversion Congress and Exposition (ECCE), 2012 IEEE, 2012, pp. 1453-1460.

[12] S. Rodrigues, R. Teixeira Pinto, P. Bauer, and J. Pierik, "Optimization of social welfare and transmission losses in offshore MTDC networks through multi-objective genetic algorithm," in Power Electronics and Motion Control Conference (IPEMC), 2012 7th International, 2012, pp. 1287-1294.

[13] R. T. Pinto, P. Bauer, S. F. Rodrigues, E. J. Wiggelinkhuizen, J. Pierik, and B. Ferreira, "A Novel Distributed Direct-Voltage Control Strategy for Grid Integration of Offshore Wind Energy Systems Through MTDC Network," Industrial Electronics, IEEE Transactions on, vol. 60, pp. 2429-2441, 2013.

[14] S. A. Soliman and A.-A. H. Mantawy, Modern optimization techniques with applications in electric power systems. New York: Springer, 2012.

[15] MATLAB, R2014a (8.3.0.532). Natick, Massachusetts: The MathWorks Inc., 2014. 